\title{
LA DURACIÓN BERGSONIANA: ANÁLISIS DE UN MODELO DE TEMPORALIDAD INTENSIVA
}

\author{
Roberto Ballester Corres \\ Universidad de Zaragoza \\ http://dx.doi.org/10.15304/ag.38.1.5009
}

\section{Resumen}

A través del análisis del concepto de duración (durée) a lo largo de la filosofía de Henri Bergson, se propone una particular filosofía del tiempo como modelo de temporalidad intensiva, vivida, heterogénea y antitética de toda explicación mecanicista, en aras de situar dicha filosofía del tiempo en una necesaria interlocución con el planteamiento teórico acerca del tiempo desde un punto de vista fenomenológico. Para ello, nos serviremos de nociones claves del pensamiento de Henri Bergson, como son: memoria intuición o vida, en su necesaria interrelación con el fenómeno de la duración, que dará cuenta de la coherencia interna del pensamiento bergsoniano y permitirá esclarecer mejor el carácter intensivo de la temporalidad. Palabras clave: Bergson, duración, memoria, intuición.

\begin{abstract}
Through the analysis of duration concept along Henri Bergson's philosophy, we propose a singular philosophy of time as a model of an intensive, lived, heterogeneous and contrary to every mechanistic explanation temporality, for the sake of placing this time philosophy on a required dialogue with the phenomenological theory about time. To that, we will make use of key notions of the Bergson's thinking, as: memory, intuition or life, on their necessary articulation with duration phaenomenon, which will be held accountable for the intimate coherence with Bergson's philosophy and it will let us to clear the intensive nature of temporality up.
\end{abstract}

Keywords: Bergson, duration, memory, intuition.

Recibido: 13/03/2018. Aceptado: 29/05/2018. 


\section{Introducción}

Madeleine Barthélemy-Madaule apunta, acertadamente en nuestra opinión, que «todo estudio sobre el bergsonismo debe partir de la duración (durée) » ${ }^{1}$, lo cual no viene sino a apuntar que todo el pensamiento bergsoniano está construido bajo la propuesta de una concepción del tiempo inmanente, que se inserta primeramente $-\mathrm{y}$, podríamos decir, de manera más radical- en los estados de conciencia, construyéndose más negativa que positivamente, más crítica que afirmativamente, más intuitiva que teóricamente.

No obstante-vamos a sostener a lo largo del artículo- una lectura atenta al concepto bergsoniano de duración nos hará descubrir la propuesta de un modelo de temporalidad radicalmente irreductible a esfera cuantitativa alguna, yendo en su propuesta, en este sentido, más allá (o más acá) respecto a la fenomenología husserliana y la fenomenología hermenéutica heideggeriana a la hora de plantear la imposible espacialización de la temporalidad, dando pie a una temporalidad que si ha de adjetivarse, sólo podrá pensarse como tiempo intensivo, en contraste con toda posibilidad de extensión. Este carácter intensivo del tiempo debe entenderse tanto en el sentido cualitativo que las diferencias de intensidad sugieren, como stricto sensu en su calidad de sentido frente a la referencialidad externa de la extensión. Se sugiere con esta denominación, por tanto, aquello que va a estar de fondo en todas las tematizaciones de la duración a lo largo de las obras de Bergson: que la duración no es sino la denominación, a falta de un nombre menos equívoco, de un tiempo vivido (temps vécu), experimentado, alejado de toda representación espacial y, por tanto, lineal, al que sólo se puede acceder auténticamente al atender a la duración misma, al modo husserliano, de la corriente de conciencia.

Con ello, pretendemos que este artículo contribuya a una recuperación de la filosofía bergsoniana, alejándola, en cierta manera, de su exégesis como filosofía de la vida de carácter espiritualista, tal y como se ha comprendido tradicionalmente la escuela francesa del "bergsonismo". A pesar de que Bergson elabora su filosofía dentro de ese caldo de cultivo del espiritualismo, que nace como reacción al positivismo, el cientificismo y la psicofísica, siendo innegable la influencia de Jules Lachelier y de Félix Ravaisson, una atención renovada a los planteamientos filosóficos influidos por la idea misma de duración desde la óptica bergsoniana permite

\footnotetext{
${ }^{1}$ M. Barthelemy-Madaule, Bergson, Paris, PUF, 1968, p. 16.
} 
replantear la proyección y fecundidad filosófica de esta nueva concepción de la temporalidad. Estas influencias se nos antojan asimismo reveladoras, permitiendo una exégesis filosófica del concepto de duración desde su misma óptica (pero sin abandonar la tematización propia de la obra bergsoniana), dejando de lado la interpretación espiritualista a la hora de afrontar el análisis del pensamiento de Bergson. Así pues, la influencia de Bergson en figuras como Martin Heidegger, Eugène Minkowski, Maurice MerleauPonty, Jean-Paul Sartre, Paul Ricoeur o Gilles Deleuze nos da pie a pensar la necesidad de volver a una filosofía como la de Bergson para poner encima de la mesa la fecundidad y radicalidad de un planteamiento de tiempo como es el de la duración bergsoniana.

\section{La cuantificación del tiempo como duración impura y homogénea}

En la filosofía bergsoniana, las explicaciones científico-naturales acerca del tiempo no sólo son insuficientes, sino que no captan en absoluto lo temporal del tiempo, esto es, la duración real que no puede en ningún caso, si queremos preservar su naturaleza durable misma, reducirse a representaciones cuantitativas que sólo van a presentar, en cambio, una yuxtaposición secuenciada de magnitudes extensivas. Un planteamiento extensivo y objetivable sobre el tiempo, del tipo que sea, no puede plantearse sin correr el riesgo de mencionar una espacialidad que no da cuenta del carácter cambiante, móvil, heterogéneo y al mismo tiempo ininterrumpido, que es propio de una noción de temporalidad como la que nos plantea Henri Bergson. Pero, ¿por qué sería pertinente, desde la óptica bergsoniana, abandonar una noción de tiempo mensurable y extenso en favor de la duración? La idea de la duración surge como reacción a la lógica aritmética de las agujas del reloj, en contra, por tanto, de la reducción del tiempo a la variable $t$ tal y como ha sido planteada por la física de herencia newtoniana y en contra, pues, del tiempo como cuarta dimensión espacial en la teoría de la relatividad de Einstein -con el que tuvo un intenso debate el 6 de abril de 1922 en la Sociedad Francesa de Filosofía-. Este tiempo inauténtico, este tiempo del minutero, no hace sino modular el tiempo en una multiplicidad homogénea de unidades mensurables; lleva a cabo un cálculo de magnitudes temporales que se suceden una tras otra. Así, acudiendo precisamente a la noción de número, Bergson lo define, en su tesis doctoral, como una sucesión de unidades y, a la vez, una unidad en sí misma, por ser la síntesis de esas unidades que encierra. Así, nos dirá Bergson, «no basta decir que el número es una colección de unidades; hay que añadir que esas unidades son idénticas 
cuando se las cuenta ${ }^{2}$. Se nos ofrece, pues, una multiplicidad de unidades homogéneas, siempre idénticas en sí mismas, basadas en la homogeneidad inherente a toda cantidad.

Dicho de otra forma, lo que desde la perspectiva heideggeriana es entendido como un tiempo-ahora, como un uno-tras-otro de ahoras, aquí es visto de forma semejante ${ }^{3}$; se insiste en el carácter cuantitativo de dichas unidades, el carácter, por tanto, acumulativo que posee el tiempo mecánico, situando como una de las principales características de esta duración impu$r a$ la yuxtaposición propia de dicha secuencia de magnitudes cuantitativas. A partir de una especial atención a las aporías eleáticas, Bergson establecerá la intrínseca "muerte" del tiempo fruto de su espacialización, que surge no ya sólo de una representación espacial del mismo, sino también de la propia consideración de la duración como secuencia de unidades que sólo puede entenderse como una yuxtaposición de las mismas (bajo la forma de un ahora tras otro, de un instante que da paso a otro instante en una lógica serial). Tal y como define de forma esclarecedora el propio Bergson en $\mathrm{La}$ evolución creadora (1907): «el mundo sobre el que opera el matemático es un mundo que muere y renace a cada instante» ${ }^{4}$. Esta muerte abismática entre instante e instante que hace imposible, para el filósofo francés, una verdadera sucesión, es habitualmente pasada por alto por aquello que, en esta obra, Bergson denomina "el mecanismo cinematográfico del pensamiento y la ilusión mecanicista”, en la cual la inteligencia acciona su comprensión usual a partir de una pretendida sucesión de cuasi-instantáneas. Como se hará explícito más adelante, existe una intrínseca relación entre dicha ilusión mecanicista y la categoría epistemológica, en la obra de Bergson, de la "inteligencia", facultad de comprensión que, lejos suponer una facultad que atienda a la heterogeneidad intensiva de la duración inmanen-

${ }^{2} \mathrm{H}$. Bergson, Ensayo sobre los datos inmediatos de la conciencia, Salamanca, Sígueme, 1999 , p. 62.

${ }^{3}$ Tal y como señala Heath Massey, a propósito de la influencia bergsoniana en el planteamiento de la temporalidad en Heidegger: «Even though Heidegger appears to be most concerned with distancing himself from Bergson, his strategy for dealing with time displays a profound engagement with Bergson (...). However, like Bergson, Heidegger seeks to show that certain assumptions about time are at the basis of some of philosophy's most fundamental and persistent problems. As such, Heidegger and Bergson are united in not only challenging the way philosophers have traditionally thought about time, but also indicating new directions for philosophy by thinking through time», H. Massey, The Origin of Time: Heidegger and Bergson, New York, State University of New York Press, 2015, p. 3.

${ }^{4}$ H. Bergson, La evolución creadora, Buenos Aires, Cactus, 2007, p. 41 [cursiva en original]. 
te a la conciencia, supone un acto de entendimiento que opera siempre por reducción objetiva del fenómeno ${ }^{5}$. Lo que obtenemos es, desde esta ilusión mecanicista, a la que más adelante volveremos, lejos de una comprensión de la duración de los estados de conciencia, un constante reemplazo de instantes disruptivos unos respecto a los otros, cuya objetivación impide entender la especificidad de lo durable al solidificarla en la yuxtaposición de unidades extensivas de magnitud, de tal modo que este tiempo tratado objetiva y extensamente:

Recomenzaría indefinidamente, e indefinidamente yuxtapondría vistas a vistas, sin obtener otra cosa. Así pues, la aplicación del método cinematográfico desembocará aquí en un perpetuo recomienzo en el que el espíritu, no encontrando nunca satisfacción y no viendo en parte alguna dónde posarse, se persuade sin duda a sí mismo que mediante su inestabilidad imita el movimiento mismo de lo real ${ }^{6}$.

Vemos, pues, que nace aquí una ilusión de movimiento, de verdadera duración -aquí, lato sensu, en su sentido habitual de la durabilidad de un movimiento entre dos posiciones fijas- que se produce por el carácter acumulativo, sumario, de un tiempo uniforme. En el sentido que el aparato cinematográfico tiene, no puede haber verdadera sucesión porque en la yuxtaposición entre instante (posición en su reverso espacial) e instante encontramos siempre una equidistancia por la que el tiempo muere y renace a cada instante, una ausencia por tanto de duración. En este sentido, la duración impura deviene duración irreal, ilusión de duración, ilusión de tiempo. No obtenemos, pues, sino un cambio de cortes inmóviles en este tiempo abstracto homogéneo: nunca movilidad en sí misma, nunca durabilidad en tanto cual, sino la adición de un corte inmóvil tras otro corte inmóvil.

Así, lo que obtenemos, en retroyección, es que dicha duración impura lo es porque requiere de una representación espacial para existir, de una espacialidad que marca incluso, deberíamos decir, la falsedad misma, la ilusión, de esta concepción extensiva de la temporalidad. Como bien señala Ignacio Izuzquiza: «la oposición radical entre tiempo y espacio es oposición radical entre duración y simultaneidad, entre reversibilidad e irreversibilidad, entre homogeneidad y heterogeneidad ${ }^{7}$. Por otro lado, donde hay yux-

${ }^{5}$ Veremos más adelante el sentido metódico de la intuición como vía de acceso originaria al fenómeno de la duración en sí misma. Acerca de la relación entre estas facultades del pensamiento con una diferenciación dual de dos tipos de sujeto, vid. I. Ceberio De León, "El sujeto en Bergson", en Daimon, supl. 1 (2007), p. 53: «El sujeto objetivado es fruto de la inteligencia mientras que el sujeto subjetivado es fruto de la intuición».

${ }^{6}$ H. Bergson, La evolución creadora, cit., p. 309.

${ }^{7}$ I. Izuzquiza, Henri Bergson: la arquitectura del deseo, Zaragoza, Prensas Universitarias de Zaragoza, 1986, p. 32. 
taposición, existe una representación espacial; donde hay magnitud, hay homogeneidad y extensión; donde hay espacialidad y extensión, por tanto, hay simultaneidad de todos los momentos yuxtapuestos y, de ahí, reversibilidad. Nada de estas características definen lo temporal stricto sensu, sino una desviación hacia una espacialidad de carácter objetivo, externa a todo vivenciar el tiempo. Sin embargo, esta relación sinonímica entre espacialidad y extensión plantea una pregunta que es necesario intentar responder: ¿la asimilación del espacio como extensión inerte trae consigo, en el fondo, una involuntaria suposición de las doctrinas positivistas que se pretenden criticar; o bien, por el contrario, es la constatación de la imposibilidad de una temporalidad pura por parte de esas doctrinas en su intento de explicar el tiempo y el espacio como una misma cosa? A pesar de que, ciertamente, en el Ensayo esa relación entre espacialización y extensión se aborda, se hace, no obstante, a partir del análisis de lo que Bergson denomina "magnitud intensiva", que desde una crítica a la psicofísica se explica como una confusión entre la intensidad y la extensión al efectuar una cuantificación de los estados de conciencia que se resisten a ser reducidos a una multiplicidad homogénea y no heterogénea.

Así, vemos que, en su crítica a todo tiempo objetivado, Bergson encuentra dos variantes distintas de cómo el flujo puro e indivisible de la duración es interrumpida. Por un lado, la mensurabilidad de ese tiempo provoca, ejemplificado por Bergson a través de las aporías eleáticas, que el tiempo se reduzca a la yuxtaposición de un momento detrás de otro, de una cantidad después de otra, creando una ilusión de sucesión y nunca un verdadero flujo de tiempo. Por otro lado, la espacialización provoca que todo el tiempo se nos dé simultáneamente y, por tanto, sin devenir alguno. Tanto la fragmentación del tiempo en ora cantidades, ora instantes, ora minutos y segundos, como la confusión del tiempo en extensión inerte, sin movilidad, marca una aparente explicación circular: la espacialización parece surgir de la propia mensurabilidad y la mensurabilidad del tiempo parece propia de una representación espacial. Esto es, que para representar la sucesión de las cantidades temporales hemos de situar dichas magnitudes una detrás de otra en una linealidad espacial y, al mismo tiempo, la espacialización del tiempo trae consigo la posibilidad de dividir, subdividir y separar esa representación espacializada del tiempo. Por ello, la extensión mecanicista, a nuestro juicio, representa dentro del imaginario bergsoniano la identificación entre la instancia espacial y la cuantitativa, así como una identificación entre posición en el espacio, fragmentación cuantitativa y división en instantes de tiempo. Tal y como comenta Deleuze a este respecto, «no hay otra 
definición de mecanicismo que la que invoca, de igual modo, un tiempo espacializado, conforme al cual los seres representan diferencias de grado, de posición, de dimensión, de proporción» ${ }^{8}$.

\section{La duración como continuum indivisible}

Empezar por haber elaborado el análisis del concepto de duración por aquello que no es el concepto de duración ha pretendido dirigir la mirada hacia una definición de la duración en términos negativos. Esta aproximación no es aleatoria, sino que pareciera que el propio concepto de duración sólo puede aferrarse adecuadamente cuando lo determinamos como in-divisible, como in-extenso y como in-numerable. El carácter volátil, contradictorio, casi paradójico, de llevar a cabo una definición de algo que parece huir de una aprehensión de cualquier tipo, a riesgo de no estar analizando más que su fósil espacializado, no pasó desapercibido por parte de Bergson. Consecuentemente, el modo en que Bergson se enfrenta a la explicación de su concepto de duración parece huir de una explicitación sistemática de sus características e implicaciones, provocando que éste sea un concepto que vaya a transitar toda la obra de Bergson de una forma u otra, alterando el lenguaje empleado, enfocándolo desde distintas perspectivas, pero siempre con cuidado de no acabar objetivándolo, de no malograr la radicalidad de su concepto.

Por tanto, ¿cómo empezar a definir una temporalidad indivisible e inextensa? En primera instancia, no podemos definir la duración sino como un continuum temporal, como un flujo de tiempo mediante el cual podemos afirmar que algo está durando, que algo está en -permanente- proceso, un tiempo que no es el tiempo objetivo del calendario o el reloj y un tiempo que lejos de poder dividirse en instantes, se acerca más a la noción de intervalo, de secuencia ininterrumpida. En consonancia con lo que establecerá poco tiempo después Husserl, en Bergson el sentido mismo de la noción duración involucra y determina la permanencia y la identidad misma de aquello que dura. La duración es el elemento constitutivo del ser, que afirma el ser y lo afirma como flujo de tiempo irreversible e indivisible, imparable. Lejos de dividirse dimensiones temporales, delimitando claramente lo que ya ha sido, lo que es y lo que será, así como lejos de subdividirse en cuantificaciones que anularían la propia "movilidad" del flujo de tiempo que

${ }^{8}$ G. Deleuze, El bergsonismo, Madrid, Cátedra, 1987, p. 20. 
dura, Bergson define la duración, ya tardíamente, como "flujo de la vida interior", como "continuidad en derrame", como "multiplicidad de estados que se expanden". La duración es entendida fundamentalmente como flujo de la vida interior, esto es, como el flujo de los estados de conciencia. La duración pura debe entenderse, entonces, en semejanza a una noción de duración interior, esto es, una forma de tiempo como cambio y multiplicidad de intensidades, una multiplicidad cualitativa y no cuantitativa, es decir, el cambio no de posiciones y dimensiones, sino diferencias de naturaleza. Tal y como especifica Heath Marley: "qualitative succession" is not a formula for duration that Bergson himself uses. Instead, Bergson prefers the terms "qualitative multiplicity" and "continuous multiplicity" to distinguish duration from any numerical or discrete multiplicity» ${ }^{10}$.

Sin embargo, hay que considerar esta interioridad de la duración no como la duración de una intimidad en oposición dualista a la exterioridad extensiva, pues lo trascendente a la conciencia estará sometida a la misma duración que sólo puede comprenderse, otrora, desde el punto de vista de la intensión -en contra de la reducción a términos dualistas objetivosubjetivo, creemos que la dualidad que se establece es, más bien, la de lo extensivo-intensivo, de donde nace, en todo caso, una aproximación objetivista-materialista o una aproximación subjetivista-espiritualista ${ }^{11}$-. Ya en 1889 Bergson sostiene:

La sucesión de los estados por los que pasa no podría revestir para él la forma de una línea; pero sus sensaciones se agregarán dinámicamente unas a otras y se organizarán entre sí como hacen las sucesivas notas de una melodía por la que nos dejamos mecer. En resumen, la pura duración bien podría no ser sino una sucesión de cambios cualitativos que se funden, que se penetran, sin contornos precisos, sin tendencia alguna a exteriorizarse unos con relación a otros, sin parentesco alguno con el número: sería la heterogeneidad pura ${ }^{12}$.

\footnotetext{
${ }^{9}$ Vid. H. Bergson, El pensamiento y lo moviente, Buenos Aires, Cactus, 2013, p. 39, pp. 185-187.

${ }^{10} \mathrm{H}$. Massey, The Origin of Time: Heidegger and Bergson, cit., p. 51.

${ }^{11}$ Existe, precisamente, una oposición clara en Bergson tanto al idealismo como al materialismo, por considerarlas ambas posiciones reductivas del fenómeno de la conciencia, ora a la materialidad del cerebro, ora al espíritu. Como se ve reflejado en el apartado siguiente, en nociones fundamentales en la filosofía bergsoniana como son las de "percepción" (perception) y "hábito" (habitude), a pesar de lo que pueda dar a entender la radicalidad con la que se muestra la oposición duración-espacio, extensión-intensión, existe una clara interrelación entre la conciencia y el cuerpo, que se hace, otrora, desde la diferencia de naturaleza entre cerebro y mente, entre cosa (materia) y representación (mente): cfr. J. Pardo Martínez, "H. Bergson: mente y cerebro", Quaderns de filosofia i ciència, 42 (2012), pp. 115-126.

${ }^{12} \mathrm{H}$. Bergson, Ensayo sobre los datos inmediatos de la conciencia, cit., p. 79.
} 
Entender la duración pura como pura heterogeneidad va a significar que la diferencia introducida por el proceso de la duración va a ser de carácter cualitativo; o lo que es lo mismo, los estados de conciencia, en su durar, van a diferenciarse unos de otros solamente en términos cualitativos, es decir, van a presentarse como fundidos unos en otros, como pertenecientes unos a otros, todos participantes de la misma secuencia, interpenetrados entre sí sin que se delimiten sus contornos. Con ello, no obstante, queda por enfatizar que, si el fenómeno de la duración algo inaugura, en relación siempre intrínseca, como vamos a ver, con la memoria en su papel prioritario en los fenómenos de conciencia y en la intuición -como método de acceso a la duración que sólo puede entenderse como experiencia intensiva de la misma-, es una ontología de la multiplicidad heterogénea y la singularidad en tanto que diferencias de naturaleza y principios de individuación a partir de este mismo fenómeno de duración ${ }^{13}$.

\section{La memoria como unión dinámica entre las dimensiones temporales}

La noción de memoria es desarrollada por Bergson en su obra Materia y memoria (1896), la primera que será publicada tras su tesis doctoral y que continúa, como en el Ensayo, situando como campo temático los estados psicológicos de conciencia; si bien, esta vez, como el propio nombre indica, vamos a encontrar una clara pretensión de tematizar los estados de conciencia en su necesaria relación con el fenómeno del cuerpo, así como la relación, menos dual que la que pueda darse a entender desde la comprensión extensiva con respecta al mundo material, entre mente y materia. Supone, sin embargo, un progreso en la comprensión de la duración de los estados de conciencia. En efecto, al margen del estudio de la mente y el cuerpo, la noción de memoria, lejos de ser una suerte de cajón de sastre en la que se apila el pasado, surge como el acto de conciencia de un pasado dinámico que rompe con la linealidad y espacialidad de un tiempo de dimensiones temporales estancas.

Encontramos, pues, una indivisión, a propósito de la memoria, entre la dimensión pasada y la dimensión presente en la conciencia, puesto que ésta nos trae a la percepción presente el recuerdo puro (souvenir pur) del pasado. La radicalidad de la memoria en Bergson reside en que el acto de reme-

${ }^{13}$ Cfr. L. Lawlor, The challenge of Bergsonism: Phenomenology, Ontology, Ethics, London, Continuum, 2003, pp. IX-XIII. 
moración no consiste en una representación presente de un estado de conciencia retenido, que sería lo que en la terminología bergsoniana se define como recuerdo-imagen (souvenir-image) y que devendría en la codificación simbólica del movimiento mismo del pasado hacia el porvenir. Bergson viene a establecer una línea horizontal e indivisa que conecta directamente el recuerdo puro con la percepción, pasando por el filtro del recuerdo-imagen que traduce el pasado y lo convierte en imagen mental. No obstante, no se tratará en ningún caso de una identidad de naturaleza entre percepción y recuerdo. La percepción siempre será mediada por la imagen como modo de aprehensión del objeto. La relación entre percepción y memoria, como bien señala Jesús Pardo: "consistirá en una inserción regular de recuerdos en las percepciones. Pero no como pretende el asociacionismo: la percepción en busca del recuerdo, sino al contrario, el recuerdo situándose sobre la percepción como medio de profundización y análisis del objeto» ${ }^{14}$.

Vemos que la memoria bergsoniana se encuentra lejos de la asociación de percepciones pasadas en una percepción presente -bien sea por semejanza (ressemblance) o por contigüidad (contiguïté) $)^{15}$-, presentando una memoria siempre presente en toda percepción: "toda percepción es ya memoria» ${ }^{16}$. Cabe señalar, empero, que la noción de imagen va a ser de gran relevancia a lo largo de Materia y memoria. Esta noción no mienta un acto de la fantasía o la imaginación, pues todo contenido perceptivo es ya imagen. Como bien señala Deleuze, a propósito de la pretensión fundamental de esta obra: "hay que intentar reencontrar una actitud en la cual podríamos captar esta identidad extraña de la imagen, del movimiento y de la materia, que no es la actitud ingenua, que tampoco es la actitud erudita» ${ }^{17}$, que será la actitud de la intuición filosófica, a la que atenderemos más adelante. Nos encontramos, nos dirá Bergson, ante imágenes que son percibidas en cuanto abrimos los sentidos y que interactúan y se interrelacionan unas con otras, configurando una percepción en constante afectación por el pasado traído al presente por la memoria y, por tanto, un presente siempre experimentado como imagen que es siempre recuerdo-imagen ${ }^{18}$. En palabras de Leonard Lawlor: «Bergsonism differs from phenomenology by means of its concept

${ }^{14}$ J. Pardo Martínez, “H. Bergson: mente y cerebro”, cit., p. 118.

${ }^{15}$ Vid. H. Bergson, Materia y memoria. Ensayo sobre la relación del cuerpo con el espíritu, Buenos Aires, Cactus, 2006, p. 178.

${ }^{16}$ Ibidem, p. 163.

${ }^{17}$ G. Deleuze, Cine 1: Bergson y las imágenes, Buenos Aires, Cactus, 2009, p. 29.

${ }^{18}$ Vid. H. Bergson, Materia y memoria, cit., p. 33. 
of presence; the Bergsonian concept of image amounts to a new concept of presence» ${ }^{19}$.

Como se verá a continuación a propósito del hábito, hay en toda imagen la interacción del cuerpo propio, captado como una imagen-percepción, externa, o como imagen-afección, mediante la cual, propiamente, no solo captamos inmanentemente el cuerpo, sino que dicha tematización otorga una dimensión afectiva, desde el horizonte del cuerpo, a toda realidad percibida, lo cual será relevante a propósito de la relación entre intuición y duración como tiempo vivido, pues toda captación de duración será a partir de una intuición íntima, desde la duración inmanente, que en esta obra, Materia y Memoria, posee el sentido de una interrelación entre afecciones y percepciones. A propósito de dicha interrelación y en contraposición con la metáfora del aparato cinematográfico, Bergson hablará de una imagen caleidoscópica y sinestésica, en donde «no hay percepción que no pueda, por un acrecentamiento de la acción de su objeto sobre nuestro cuerpo, devenir afección ${ }^{20}$. En este contexto, las imágenes-recuerdos (o recuerdos-imagen, Bergson las emplea indistintamente), si bien también funcionan como un necesario almacenaje de la percepción presente y externa, suponen volver a traer a la imagen presente el caleidoscopio de percepciones y afecciones entre las que está involucrada, necesariamente, la acción del cuerpo.

Es por ello por lo que se establece aquí una diferenciación previa a la del recuerdo puro y el recuerdo-imagen. Se trata de la diferencia entre hábito (habitude) y memoria pura o verdadera (mémoire vraie), que parte de la previa distinción entre hábito e imagen-recuerdo, por la cual el hábito «recobra esos elementos pasados, no en imágenes-recuerdos que los evocan, sino en el orden riguroso y el carácter sistemático con que se cumplen los movimientos actuales» ${ }^{21}$, marcando una estrecha diferencia entre la posible imaginación en la que pueda caer la imagen-recuerdo y una auténtica repetición, no homogénea, siempre diferencial, del pasado en el presente: «ya no nos representa nuestro pasado; lo actúa» 22 . El papel del cuerpo, en la noción de hábito y de acción, es fundamental para entender cómo la conciencia y la intensidad planteadas no son antinómicas respecto de la propia acción y afección del cuerpo. El hábito, por ejemplo, tocar el piano, lleva a cabo un acto de memoria, de actualización del pasado que escapa a

\footnotetext{
${ }^{19}$ L. Lawlor, The challenge of Bergsonism, cit., p. 1.

${ }^{20} \mathrm{H}$. Bergson, Materia y memoria, cit., p. 67.

${ }^{21}$ Ibidem, p. 96.

${ }^{2}$ Ibidem.
} 
la idea de una mera imagen repetida en mi conciencia. Es una actualización constante del pasado que no se da por representación a través de una rememoración presentificante de la memoria-imagen. Al igual que en el caso de la percepción, en mi hábito estoy efectuando memoria. El hábito trae al presente un momento del pasado de forma activa y corporal.

Vemos cómo, pues, a propósito de la noción de memoria en todos sus significados, el pasado sólo se diferencia del presente por una diferencia de intensidad, sin que exista stricto sensu dimensiones temporales que marquen, desde una lógica presentista, la conexión puramente negativa entre el pasado que desaparece y que, en todo caso, se evoca, respecto a un acto perceptivo presente de mayor intensidad. Por el contrario, éste acto perceptivo presente siempre se efectúa desde una constante interpenetración de la memoria en él. Vemos, pues, cómo la propia distinción entre el pasado y el presente no responde a una distinción real en la propia duración, en donde el pasado y el presente se afectan mutuamente tal y como lo hacen los estados sucesivos de la conciencia durable, puesto que, en palabras de Bergson: «llega un momento en que el recuerdo así reducido se inserta tan bien en el presente que no podría decirse dónde termina la percepción, dónde comienza el recuerdo ${ }^{23}$.

\section{Intuición e intensidad: duración como tiempo vivenciado}

En este recorrido por la idea de la duración como teorización de una temporalidad de corte intensivo, nos queda ver, precisamente, en qué medida se entiende el carácter fundamentalmente intensivo de la duración en oposición a la extrapolación de la duración en nociones de tiempo con pretensión objetiva, como pueda ser la evolución. Es a partir del concepto de intuición, en su necesaria conexión, pues, con la intensidad que da pie a una comprensión del tiempo intensivo, como se pone en juego el carácter interior y simple de la duración, su carácter de tiempo-cualidad. La asimilación del concepto de duración por parte de Bergson busca remarcar el carácter intuitivo, intensivo, vivido (temps vécu) e interior de la temporalidad.

Bergson es claro al determinar que el conocimiento epistémico de la duración solamente es posible por medio de una intuición simple y directa de ella ${ }^{24}$, en contraposición con la inteligencia y la racionalización que no ha-

${ }^{23}$ H. Bergson, Materia y memoria, cit., p. 120.

24 «La intuición, en este sentido, comporta la implicación en un acto simple de una multiplicidad dada por el objeto intuido», M. Ruiz Stull, "Intuición, la experiencia y el tiempo en el pensamiento de Bergson”, Alpha, 29 (2009), p. 186. 
cen sino espacializarla. En la "La intuición filosófica", Bergson comienza a teorizar sobre la noción de intuición bajo una diferencia dialéctica respecto a la noción de inteligencia. Por un lado, Bergson entiende la inteligencia como una facultad productora de conceptos inmóviles y encajonados, traicionada constantemente por el lenguaje como fosilización de la duración y la vida; por el otro lado, la intuición no entiende de conceptualizaciones, sino que es una intuición simple e inmediata que se abre desde esa simplicidad en un plexo de relaciones y significaciones nuevas.

Cabe decir que es a partir de la crítica a la noción de inteligencia y la racionalidad lógico-deductiva por lo que Bergson ha sido, inmerecidamente, reducido a espiritualismo irracionalista y ateórico. Sin embargo, se aprecia de los análisis efectuados hasta ahora que la crítica no se dirige a toda facultad intelectiva, sino más bien a una determinada forma de reduccionismo que no da cuenta del fenómeno auténtico de la vida, que no deja expresarse en su singularidad y simple heterogeneidad a la conciencia en su flujo de duración intensiva. Deleuze sostiene que la intuición no es sino el método filosófico de Bergson. Pete A. Y. Gunter encuentra ingeniosamente un modo de entender el carácter metódico de la intuición sin que caiga, con ello, en un acto de inteligencia. Gunter sostiene el carácter metódico en el acceso mismo a la intuición, no tanto de la intuición misma como método, sino pensando en el tipo de método propio de las ciencias humanas, en clave diltheyiana, en aplicación al acceso al objeto temático de la intuición (y, por ende, la duración), es decir, prefigura en Bergson un método como conocimiento intensivo y preliminar, instrucción fáctica, análisis psicológico previo a la profundización del conocimiento de sí mismo y, por último, el fenómeno temporal de la duración misma como modo de acceso a la intuición:

Conocer un tema en profundidad, insiste Bergson, es enterarse de su temporalidad: comprender esa temporalidad en su plenitud, más que estar satisfechos con concepciones más o menos estáticas (...) Dar este paso es proceder metódicamente. Ir más allá de este punto es ir más allá de la metodología como es usualmente comprendida ${ }^{25}$.

No obstante, entendemos, Gunter opera una alteración del orden de los productos: acceder intuitivamente al fenómeno es acceder desde la perspectiva de la duración pura tal y como se nos presente intensivamente, y no, al contrario, la temporalidad como método para acceder a la intuición. Así, la intuición debe entenderse, a nuestro parecer, más que como un método en sí mismo, como una función metódica a la manera en que en la fenomenología

${ }^{25}$ P.A.Y. Gunter, "Jerarquía temporal en Bergson y Whitehead”, Thémata. Revista de Filosofía, 44 (2011), p. 330. 
hermenéutica de Heidegger la tiene la angustia, primero, o el aburrimiento, después; o a la manera en que en la fenomenología husserliana, la epojé cumple un papel metodológico fundamental: suspender la actitud natural ante los hechos y permitir la desviación de la mirada hacia lo apriorístico o, en el caso de Heidegger, hacia el sentido del ser del Dasein ${ }^{26}$.

Aquí, empero, la intuición no va a tener un papel metodológico tan remarcado, si bien va a cumplir la misma función disruptiva que solo se produce intensivamente. De lo contrario, no se entendería el carácter radicalmente opuesto al acto intelectivo de la inteligencia. En la intuición se encuentra ya el acceso a la duración propia misma. Así pues, tenemos que si la intuición es capaz de captar la duración qua duración intensiva y como creación ininterrumpida de novedad, es porque la intuición misma se identifica con la interioridad que vivencia la duración: «intuición significa entonces ante todo conciencia, pero conciencia inmediata, visión que apenas se distingue del objeto visto, conocimiento que es contacto e incluso coincidencia ${ }^{27}$, esto es, conciencia inmediata de su propia estructura temporal, que no se distingue apenas del objeto visto (intuido) porque no es sino intuición de sí, de la propia estructura temporal de la conciencia como duración: "pensar intuitivamente es pensar en duración» ${ }^{28}$.

No se trata, por tanto, de una facultad más de conocimiento (ni de un método para alcanzarlo), sino el modo en que de entrada experimentamos de forma simple y directa el proceso de nuestro yo durable. No debe confundirse la intuición con la percepción, desde la perspectiva bergsoniana, ya que esta última es la captación sensible de la realidad, que se codifica en imágenes. En cambio, es gracias a la intuición, nos dirá Bergson, como «es posible un conocimiento interior, absoluto, de la duración del yo por el yo mismo» ${ }^{29}$, una intuición irreflexiva, de simplicidad indubitable, imposible de espacializar y de dividir, que sin embargo debemos fragmentar, conceptualizar, al tenerla que explicar mediante la yuxtaposición de las palabras del lenguaje. El análisis/inteligencia anula la duración al explicarla mediante la lógica de las cosas, cayendo en la duración impura. Por el contrario, algo tan contradictorio, cambiante, siempre durando, como la tempora-

${ }^{26}$ Sobre la posibilidad de pensar la intuición en relación con el método fenomenológico, vid. H. Jacobs and T. Perri, "Intuition and Freedom: Bergson, Husserl and the movement of philosophy", en M. R. Kelly (ed.), Bergson and Phenomenology, London, Palgrave Macmillan UK, 2010, pp. 101-117.

${ }^{27} \mathrm{H}$. Bergson, El pensamiento y lo moviente, cit., p. 39.

${ }^{28}$ Ibidem, p. 42.

${ }^{29}$ Ibidem, p. 191. 
lidad, sólo puede conocerse por un gesto simple e inmediato como es la conciencia haciéndose consciente de su propio ser durable ${ }^{30}$.

Va a ser en esta inmanencia de la experiencia de la duración, por medio de la intuición tal y como ha sido apuntada, como se piensa el carácter intensivo de la duración. La intensidad, en un estado de conciencia, es comprendida como aquello captado subjetivamente y, al mismo tiempo, expresa el carácter subjetivo del fenómeno de la duración misma de los estados de conciencia: «nunca nos preguntamos con tanto atrevimiento sobre la intensidad de un estado psíquico como cuando el aspecto subjetivo del fenómeno es el único que nos afecta» ${ }^{31}$. Aquí, la diferenciación entre intensión y extensión no opera separándolas como categorías ontológicas duales, sino como caras de un mismo fenómeno bifronte, que puede ser pensado desde su carácter subjetivo-intensivo o desde su carácter material-extensivo. Sin embargo, como ya hemos visto, precisamente la radicalidad con que se plantea el concepto de duración como modelo de un concepto de tiempo que no pueda ser reducido a representación espacial alguna y, con ello, extensiva y cuantitativa, hace que: «la comparación de dos instantes [y, por tanto, su sucesión] se hace lo más frecuentemente sin la menor apreciación del número de las causas, de su modo de acción ni de su extensión» ${ }^{32}$.

Las diferencias de intensidad no son, pues, gradaciones susceptibles de cuantificación; más bien, encontramos en la intensidad la referencia a un fenómeno cualitativo, a un matiz, una "coloración" del estado de conciencia en tanto en cuanto una experiencia subjetiva o, en palabras de Bergson, la consideración de la emoción fundamental desde la que es pensable la intensidad como el modo específico en que puede pensarse la duración (como cambio, sucesión, multiplicidad heterogénea) de las intuiciones. Así, podemos comprender la intensidad desde una doble perspectiva: por un lado, mienta el modo específico en que se produce el cambio de los estados psíquicos, cambio privativamente extensivo, afirmativamente cualitativo, que lejos de ser un cambio de posición o de magnitud, se trata de un cambio profundidad, de grado de percepción, así como un progreso cualitativo y de complejidad, de heterogeneidad creciente en el seno mismo de una comprensión del cambio en tanto que diferencia esencial ${ }^{33}$; por otro lado, la

30 «Intuición, la experiencia y el tiempo, en el horizonte de la vida forman un cuadro que intercambian de modo variante sus perspectivas", M. Ruiz Stull, "Intuición, la experiencia y el tiempo en el pensamiento de Bergson”, cit., p. 190.

${ }^{31} \mathrm{H}$. Bergson, Ensayo sobre los datos inmediatos de la conciencia, cit., p. 17.

${ }^{32}$ Ibidem, p. 18.

${ }^{33}$ Vid. ibidem, pp. 30-33. 
propia intensidad marca el modo en que, partiendo de este fenómeno de la sucesión de los estados de conciencia de carácter cualitativo, se fenomena la duración inmanentemente: en ese acceso cualitativo, incluso afectivo a la sucesión inmanente de la conciencia -aunque no vamos a detenernos en ello, pues no es el objeto temático del presente artículo, encontramos en el Ensayo, a propósito de la intensidad, una tematización de las emociones como alegría y tristeza como hechos psicológicos, así como de los sentimientos estéticos-, el "espíritu" accede a la naturaleza misma de la duración pura al que no es posible en ningún caso acceder a través del carácter objetivo-extensivo de ese mismo fenómeno.

Así pues, la referencia a la vida no puede ser pensada sino como referencia a la vivencia. El tiempo de la vida no será otro que el tiempo vivido, pues toda intuición es intuición vital y todo acto de inteligencia supone una desviación mecanicista. Si bien la noción de vida está en estrecha relación con la idea de la evolución creadora y designa la propia corriente de creación constante, sobre todo en las últimas obras del filósofo francés, al mismo tiempo Bergson traza las relaciones de similitud con respecto a la propia conciencia, de tal modo que la vida, sí, designa el propio impulso de creación constante de novedad (élan vital) propio de la evolución como categoría ontológica, pero también nos aproxima a la idea de vivencia y de tiempo de la vida no como tiempo de lo orgánico o natural, sino como tiempo vivido intuitivamente. Como dirá Merleau-Ponty a propósito de la duración bergsoniana: «el tiempo soy yo, soy la duración que yo capto, hay en mí la duración que se capta a sí misma» ${ }^{34}$. La vivencia del tiempo, en su identificación con la simplicidad de la intuición de la duración, es precisamente ese captarse a sí misma por parte de la duración. Podemos entender, pues, intuición-intensión como pertenecientes a la esfera de lo afectivo: en la impaciencia, el aburrimiento, el miedo, la angustia, etc., está contenida una intuición de una temporalidad no objetivable, no mensurable, no extensiva, sino vivenciada, por tanto propia. La duración, como tal, no se expresa radicalmente ni siquiera en la idea general de un proceso continuo de creación constante, sino que ha de articularse como ese tiempo cuyo dinamismo se da y se percibe de forma cualitativa y no espacial, un tiempo que, constituyendo el yo, se expresa a sí mismo por medio de la vivencia intensiva y cualitativa de ese tiempo.

${ }^{34}$ M. Merleau-Ponty, "Bergson haciéndose”, en Signos, Barcelona, Seix Barral, 1964, p. 225. 


\section{Conclusión}

Se ha pretendido articular una aproximación a la filosofía de Bergson desde la reivindicación de una noción, la de duración, que no sólo supone el pilar fundamental de todo el pensamiento bergsoniano, sino que, creemos, supone una aproximación de pretendida radicalidad al fenómeno del tiempo. Con ello, buscamos no sólo volver a traer a la palestra un pensador exitoso antaño pero denostado hoy en día, cuya filosofía fue vista por el propio Husserl como el intento fallido o al menos solo aparente de poner en claro la intuición del tiempo: «nosotros [los fenomenólogos] somos los bergsonianos consecuentes ${ }^{35}$. También, hemos pretendido articular un modelo de temporalidad intensiva, de tiempo vivido, como el que propone Bergson con su concepto de duración que, creemos, ha resultado muy influyente, aunque sea de forma distanciada y crítica, en la fenomenología heideggeriana y puede resultar de gran relevancia para las investigaciones actuales en los campos de la fenomenología genética, la teoría de la afectividad o los estudios psicopatológicos a propósito de las desviaciones en la vivencialidad del tiempo (a este propósito, hay que señalar la influencia fundamental que el pensamiento de Bergson tiene en una figura imprescindible para la psicopatología como es Eugène Minkowski) ${ }^{36}$.

Así, creemos que hemos constatado hasta qué punto su pensamiento no responde a la categorización de la concepción tradicional del tiempo desde Aristóteles a la que Heidegger reduce el planteamiento bergsoniano ${ }^{37}$ (quien insiste, asimismo, en el fracaso bergsoniano a la hora de plantear la radical diferencia entre el tiempo cualitativo y el espacio extensivo ${ }^{38}$.

${ }^{35}$ Comentario pronunciado por Husserl en 1911 en la Sociedad de Filosofía de Gotinga tras una conferencia sobre Bergson de Alexandre Koyré, recogida en castellano por A. Serrano de Haro, "Presentación de la edición española", en E. Husserl, Lecciones de fenomenología de la conciencia interna del tiempo, Madrid, Trotta, 2002, p. 12.

${ }^{36}$ Cfr. E. Minkowski, El tiempo vivido. Estudios fenomenológicos y psicológicos, México, FCE, 1973.

${ }^{37}$ El reduccionismo en la lectura heideggeriana del concepto de tiempo que subyace a la noción de duración en Bergson, en su intento por situarla en la herencia del concepto de tiempo físico y de dynamis aristotélicos, ha sido detenidamente trabajado y criticado por H. Massey, quien sostiene: «Despite a sustained engagement with Bergson's thought lasting through his early Freiburg and Marburg periods, Heidegger dismisses Bergson in Being and Time for failing to rethink time radically enough", H. Massey, The Origin of Time: Heidegger and Bergson, cit., p. 49.

${ }^{38}$ Cfr. M. Heidegger, Ser y tiempo, Madrid, Trotta, 2003, pp. 39, 348; M. Heidegger, Los problemas fundamentales de la fenomenología, Madrid, Trotta, 2000, p. 282: «Intenta ir 
La propuesta bergsoniana de una temporalidad cualitativa, heterogénea, en la que las dimensiones del tiempo son extáticas y siempre fusionadas, y en la que el tiempo se nos presenta en todo momento como un tiempo vivido intuitivamente, ha de entenderse como un hito en la filosofía del tiempo, la inauguración de una forma de pensar sobre el tiempo alejada tanto de modelos positivistas como metafísicos, en un esfuerzo de comprensión del tiempo qua tiempo, el intento absoluto de no caer en esferas explicativas que no den cuenta de la singularidad del tiempo. Podemos entender, por tanto, esta pretensión de fidelidad como la respuesta a una incredulidad: la de que la ciencia y la tradición filosófica, queriendo estudiar el fenómeno del tiempo, habían conducido su mirada a nada más alejado del mismo.

Más allá de las posibles deficiencias teóricas de un planteamiento como el bergsoniano, fruto en gran medida de su pretendida huida de la sistematización, de la rigurosidad lógico-deductiva en su pretensión de llenar de intuiciones de duración sus propios textos, llevar a cabo una lectura de su obra, bajo el prisma de la fenomenología husserliana y heideggeriana, pero sin pretender alejar el análisis de sus propias tematizaciones, permite poner encima de la palestra una filosofía como la de Bergson dedicada, casi por entero, a pensar el tiempo (vivido) en su radicalidad fenomenológica.

\section{Bibliografía}

Barthelemy-Madaule, M., Bergson, Paris, PUF, 1968.

Bergson, H., Ensayo sobre los datos inmediatos de la conciencia,Salamanca, Sígueme, 1999.

Bergson, H., Materia y memoria. Ensayo sobre la relación del cuerpo con el espíritu, Buenos Aires, Cactus, 2006.

Bergson, H., La evolución creadora, Buenos Aires, Cactus, 2007.

Bergson, H., El pensamiento y lo moviente, Buenos Aires, Cactus, 2013.

Ceberio de León, I., "El sujeto en Bergson”, en Daimon, supl. 1 (2007), pp. 53-59.

Deleuze, G., El bergsonismo, Madrid, Cátedra, 1987.

Deleuze, G., Cine 1: Bergson y las imágenes, Buenos Aires, Cactus, 2009.

más allá del concepto vulgar de tiempo y distinguir frente al tiempo entendido vulgarmente, que él denomina temps, la durée, la duración (....). Tampoco es sostenible en este sentido el concepto opuesto al concepto de tiempo vulgar, la duración. Con este concepto no logra acceder al fenómeno peculiar del tiempo». 
Gunter, P.A.Y., "Jerarquía temporal en Bergson y Whitehead”, Thémata. Revista de Filosofía, 44 (2011), pp. 326- 342.

Heidegger, M., Los problemas fundamentales de la fenomenología, Madrid, Trotta, 2000.

Heidegger, M., Ser y tiempo, Madrid, Trotta, 2003.

Husserl, E., Lecciones de fenomenología de la conciencia interna del tiempo, Madrid, Trotta, 2002.

Izuzquiza, I., Henri Bergson: la arquitectura del deseo, Zaragoza, Prensas Universitarias de Zaragoza, 1986.

Kelly, M. R. (ed.), Bergson and Phenomenology, London, Palgrave Macmillan UK, 2010. https://doi.org/10.1057/9780230282995

Lawlor, L., The challenge of Bergsonism: Phenomenology, Ontology, Ethics, London, Continuum, 2003.

Massey, H., The Origin of Time: Heidegger and Bergson, New York, State University of New York Press, 2015.

Merleau-Ponty, M., "Bergson haciéndose”, en Signos, Barcelona, Seix Barral, 1964, pp. 221-233.

Minkowski, E., El tiempo vivido. Estudios fenomenológicos y psicológicos, México, FCE, 1973.

Pardo Martínez, J., "H. Bergson: mente y cerebro", Quaderns de filosofia i ciència, 42 (2012), pp. 115-126.

Ruiz Stull, M., "Intuición, la experiencia y el tiempo en el pensamiento de Bergson”, Alpha, 29 (2009), pp. 185-201. 